\title{
Analysis of bortezomib inhibitor docked within the catalytic subunits of the Plasmodium falciparum 205 proteasome
}

\author{
Settu Sridhar, Gayathri Bhat and Kunchur Guruprasad*
}

\begin{abstract}
The three-dimensional fold of Plasmodium falciparum (Pf) 205 proteasome is similar to yeast Saccharomyces cerevisiae 205 proteasome. The twenty eight subunits complex corresponding to two copies of seven distinct a and seven distinct $\beta$ subunits shares $>35 \%$ sequence identity with equivalent subunits of the yeast 20 s proteasome. Bortezomib (Velcade ${ }^{\circledast}$ ) - a known inhibitor of the three catalytic subunits; $\beta 1, \beta 2, \beta 5$ of the yeast 205 proteasome can bind in the equivalent subunits of the Pf $20 \mathrm{~S}$ proteasome and is in agreement with experimental results. The model defines the binding mode of the bortezomib inhibitor within the catalytic subunits of the Pf 205 proteasome and provides the structural basis for the design of Pf 205 proteasome-specific inhibitors. The substitutions associated within the catalytic subunits of Pf $20 S$ proteasome relative to yeast $20 S$ proteasome; Thr21-Ser, Thr22-Ser, Thr31-Ser, Thr35-Asn, Ala49-Ser (in $\beta 1$ subunit), Ser20-Ala, Gln22-Glu ( $\beta 2$ ) and Thr21-Ser, Ala22-Met, Gln53-Leu ( $\beta 5$ ) may influence the relative caspase-like, tryptic-like and chymotryptic-like activities of the Pf 205 proteasome. The plasmodia-specific 'large' insert comprising fifty four amino acid residues (in $\beta 1$ subunit) of the Pf 205 proteasome is distant from the catalytic sites.
\end{abstract}

Keywords: Plasmodium falciparum; 20 s proteasome; Catalytic sites; Bortezomib inhibitor; Binding pockets; Plasmodia-specific insert

\section{Introduction}

An essential element of the protein quality control machinery in cells is the ubiquitin-proteasomal system (Hershko \& Ciechanover 1998; Pickart 2001; Myung et al. 2001). Proteasomes (Wolf \& Hilt 2004) are protein degradative machines found in the nucleus and cytoplasm of all eukaryotic organisms and archaebacteria and is a highly organized protease complex comprising a catalytic $20 \mathrm{~S}$ core particle (CP) and two 19S regulatory particles (RP), which together form the $26 \mathrm{~S}$ structure. The core particle degrading machinery in yeast Saccharomyces cerevisiae $20 \mathrm{~S}$ proteasome is coded by fourteen genes and two copies of these constitute the twenty eight subunits in the complex. The $26 \mathrm{~S}$ proteasome multi-subunits complex is the final destination for selective degradation of majority of cellular proteins and is responsible for the degradation of most ubiquitylated proteins through a multistep process

\footnotetext{
* Correspondence: guru@ccmb.res.in

Bioinformatics, Centre for Cellular and Molecular Biology, Hyderabad 500 007,
} India

involving recognition of the polyubiquitin chain, unfolding of the substrate, and translocation of the substrate into the active site in the cavity of the CP. The structure, function, assembly and catalytic mechanism of the proteasome are reviewed in (Jung \& Grune 2012; Saeki \& Tanaka 2012; Coux et al. 1996; Marques et al. 2009). The crystal structures of yeast $20 \mathrm{~S}$ proteaseome (Groll et al. 1997) and bovine $20 \mathrm{~S}$ proteasome (Unno et al. 2002) are available in the Protein Data Bank (PDB) (Rose et al. 2013). The crystal structure of the core particle in eukaryotic yeast Saccharomyces cerevisiae, has a barrel-shaped cylindrical structure that is comprised of four heptameric rings $\left(\alpha_{1-7} \beta_{1-7} \beta_{1-7} \alpha_{1-7}\right)$, in which each subunit is different from the other and individual subunits are uniquely located in the three-dimensional structure of the complex (Groll et al. 1997). The $\alpha$-ring on the outer sides functions as a gate for the substrate to enter while the $\beta$-ring has the proteolytic activity. In yeast $20 \mathrm{~S}$ proteasome, the $\beta 1, \beta 2$ and $\beta 5$ subunits are known to possess catalytic activity, where $\beta 1$ subunit mediates the peptidyl-glutamyl peptide 
hydrolyzing post-acidic (caspase-like) activity; $\beta 2$ subunit the post-basic (trypsin-like) activity and the $\beta 5$ subunit post-hydrophobic (chymotrypsin-like) activity (Arendt \& Hochstrasser 1997; Heinemeyer et al. 1997). The proteasomes share the fold and a novel catalytic mechanism with an N-terminal nucleophilic threonine and therefore placed in the family of Ntn ( $\mathrm{N}$ terminal nucleophile) hydrolases (Bochtler et al. 1999). The crystal structure of bovine $20 \mathrm{~S}$ proteasome revealed an additional novel catalytic subunit - the $\beta 7$ subunit (Unno et al. 2002). In addition to the $20 \mathrm{~S}$ core proteasome, the yeast $26 \mathrm{~S}$ proteasome comprises two regulatory subcomplexes containing nineteen subunits (referred as 19S regulatory complex); six Rpt (Regulatory particle ATPases) and thirteen RPN (Regulatory particle Non-Atpases) attached at terminal ends of the central portion and in opposite orientations (DeMartino \& Slaughter 1999; Voges et al. 1999). The complete subunit architecture of the yeast regulatory particle provides a model for the recognition, deubiquitination and engagement of a polyubiquitinated substrate by the $26 \mathrm{~S}$ proteasome (Lander et al. 2012). The molecular architecture of the $26 \mathrm{~S}$ holocomplex has been determined by an integrative approach based on data from cryoelectron microscopy, X-ray crystallography, residue-specific chemical cross-linking, and several proteomic techniques (Lasker et al. 2012; Förster et al. 2010; Nickell et al. 2009). Proteasomes are central to many cellular processes as they are responsible for the cytoplasmic turnover of a number of proteins and therefore manipulating the proteasomal activity is considered a key goal in controlling the stability of regulatory proteins (Groll \& Huber 2004; Kisselev \& Goldberg 2001). The observation that proteasome inhibitors cause apoptosis in certain tumor-derived cell lines has led to their application as potential cancer therapeutics (Adams et al. 1998). Bortezomib (Velcade ${ }^{ø}$ ) has been approved for treatment of multiple myeloma patients (Ludwig et al. 2005; Richardson et al. 2005; Teicher et al. 1999). The proteasome is a potential target for treating many infections and diseases (Dahlmann 2007).

In plasmodia two $\mathrm{T} 1$ threonine peptidase systems are known to be present; the $20 \mathrm{~S}$ proteasome is enzymatically active and expressed throughout the live cycle, whereas the PfhsIV is expressed in late stages of development only (Mordmüller et al. 2006). The emergence and spread of Plasmodium falciparum resistance to almost all available antimalarial drugs has necessitated the search for new chemotherapeutic compounds. It has been shown that the $20 \mathrm{~S}$ proteasome is expressed and catalytically active in plasmodia and treatment with proteasome inhibitors arrests parasite growth and therefore inhibition of the proteasome is considered to be a highly promising strategy to develop new antimalarials (Kreidenweiss et al. 2008).
A three-dimensional model of the twenty eight subunits complex corresponding to the core particle (CP) of Plasmodium falciparum (Pf) is currently not available, although individual models for twelve of the fourteen genes of the $\mathrm{CP}$ are available in the ModBase database (Pieper et al. 2011). Bortezomib, a peptide boronate, is the only proteasome inhibitor in clinical use so far. In contrast to multiple myeloma treatment (Rajkumar et al. 2005), its activity in P. falciparum laboratory strains is low (Kreidenweiss et al. 2008). The crystal structure of yeast 20S proteasome bound to bortezomib (Groll et al. 2006) is available in the PDB. Therefore, in order to evaluate the mode and affinity of binding of the bortezomib inhibitor within the equivalent catalytic subunits of the Pf $20 \mathrm{~S}$ proteasome, we have constructed a threedimensional model based on the crystal structures of the homologous yeast and bovine $20 \mathrm{~S}$ proteasomes and docked bortezomib within the catalytic subunits of the Pf $20 \mathrm{~S}$ proteasome model. Further, we have identified substitutions within the catalytic subunits of the Pf $20 \mathrm{~S}$ proteasome relative to the yeast $20 \mathrm{~S}$ proteasome. Our models of the Pf $20 \mathrm{~S}$ proteasome complexed with the bortezomib inhibitor provide a structural basis for further design of Pf $20 \mathrm{~S}$ proteasome-specific inhibitors that has implications for the treatment of malaria.

\section{Materials and methods}

Selection and identification of Pf 20 S proteasome subunit sequences

The Pf proteasome subunit sequence codes were selected from the PlasmoDB database (Aurrecoechea et al. 2009). Their equivalent codes from the UniProt database (The UniProt Consortium 2010) were also identified. The homologs of these subunits corresponding to proteins of known three-dimensional structure were identified from the PDB using the PSI-BLAST program (Altschul et al. 1997).

\section{Construction \& validation of the Pf 20 S proteasome and docking of bortezomib within the catalytic subunits}

The crystal structures of the yeast 20S proteasome (PDB code:1RYP) (Groll et al. 1997) and bovine 20S proteasome (PDB code:1IRU) (Unno et al. 2002) were used as templates in the comparative protein modeling software program MODELER (Eswar et al. 2008) for constructing a three-dimensional model of the Pf $20 \mathrm{~S}$ proteasome. The individual Pf $20 \mathrm{~S}$ proteasome subunit sequences were aligned along with their equivalent sequences in yeast and bovine $20 \mathrm{~S}$ proteasomes. MODELER constructs a 3-D model for the query sequence using sequence-to-template alignment and the satisfaction of spatial restraints derived from the template structure(s) (Sali \& Blundell 1993). The overall quality of the protein model was evaluated using the PROCHECK 
program (Laswoski et al. 1993). All pictures were generated using PyMol http://sourceforge.net/projects/pymol/. The docking of bortezomib inhibitor was carried out using AutoDock (Morris et al. 2009). In order to validate our docking studies, the coordinates of bortezomib was removed from the crystal structure of the yeast $20 \mathrm{~S}$ proteasome (PDB code: 2F16). A model of the yeast $20 \mathrm{~S}$ proteasome with bortezomib docked within the catalytic subunits using AutoDock was generated. The docked complex was structurally superimposed on to the crystal structure complex of yeast $20 \mathrm{~S}$ proteasome with bound bortezomib in the three catalytic subunits; $\beta 1, \beta 2$ and $\beta 5$ (PDB code: 2F16). The binding mode of bortezomib and inter-molecular interaction energies within the three catalytic subunits of the yeast $20 \mathrm{~S}$ proteasome were evaluated. Upon successfully reproducing the bortezomib binding in the yeast $20 \mathrm{~S}$ proteasome, bortezomib was then docked in the equivalent catalytic subunits of the Pf $20 \mathrm{~S}$ proteasome model. The binding mode and intermolecular interaction energies were once again evaluated and compared with results obtained for bortezomib binding in the yeast $20 \mathrm{~S}$ proteasome.

\section{Comparison of the catalytic sites, substrate binding} pockets and bortezomib binding in 3-D models of Pf $20 \mathrm{~S}$ proteasome and crystal structure complex of yeast $20 \mathrm{~S}$ proteasome

The residues important for the catalytic activity, substrate binding pockets and maintenance of stability of the conformation of Thr1 via hydrogen bond essential for the Ntn hydrolases was obtained from the crystal structure of the yeast 20S proteasome (PDB code: 1RYP). Further, the interactions made by the bortezomib inhibitor in the catalytic subunits of the yeast $20 \mathrm{~S}$ proteasome were obtained from (Groll et al. 2006) and LigPlot diagrams (Wallace et al. 1995) for the crystal structure of the yeast $20 \mathrm{~S}$ proteasome with bortezomib inhibitor (PDB code:2F16). The amino acid sequences corresponding to the individual catalytic subunits from yeast, bovine and Pf $20 \mathrm{~S}$ proteasomes were aligned using the CLUSTALW program (Thompson et al. 1994). The molecular graphics software spdview (Guex \& Peitsch 1997) was used to generate the hydrogen-bond interactions between the bortezomib inhibitor and residues in the binding pockets of the yeast and Pf $20 \mathrm{~S}$ proteasomes.

\section{Results and discussion}

The accession codes corresponding to the individual subunit sequences of Pf $20 \mathrm{~S}$ proteasome are shown in Table 1. The homologous chains in yeast and bovine $20 \mathrm{~S}$ proteasomes and the ModBase IDs corresponding to 3-D models available for subunits are listed.

The Pf 20 S proteasome subunit sequences share $>35 \%$ sequence identity with equivalent subunits in yeast and bovine $20 \mathrm{~S}$ proteasomes. Certain regions excluded in the model and listed in Table 2, mainly correspond to the $\mathrm{N}$ terminal regions of the catalytic $\beta$-subunits. These regions are processed at the Gly-Thr1 site during the formation of the active core proteasome. Further, the $\beta 1$ and $\beta 7$ subunits comprise certain 'large' insertions in the middle of the subunit sequences and these were also excluded in the model

Table 1 Plasmodium falciparum 20S proteasome subunit sequences, UniProt accession codes and equivalent PlasmoDB IDs

\begin{tabular}{|c|c|c|c|c|c|}
\hline S.No. & $\begin{array}{l}\text { UniProt accession codes } \\
\text { for Pf20S proteasome } \\
\text { sequences }\end{array}$ & $\begin{array}{l}\text { PDB chains corresponding to } \\
\text { yeast homologous subunits for } \\
\text { Pf } 20 \text { S proteasome sequences }\end{array}$ & $\begin{array}{l}\text { PDB chains corresponding to } \\
\text { bovine homologous subunits for } \\
\text { Pf } 20 \text { S proteasome sequences }\end{array}$ & $\begin{array}{l}\text { PlasmoDB_ID for } \\
\text { Pf } 20 \text { S proteasome } \\
\text { subunits }\end{array}$ & $\begin{array}{l}\text { ModBase_ID for Pf } \\
20 \text { S proteasome } \\
\text { subunit 3-D models }\end{array}$ \\
\hline 1 & Q81261 & $1 \mathrm{RYP} / \mathrm{J} / \mathrm{X}$ & $1 \mathrm{IRU} / \mathrm{J} / \mathrm{X}$ & PF3D7_0108000 & PFA0400c 3202 \\
\hline 2 & Q8IDG3 & 1RYP/C/Q & 1IRU/C/Q & PF3D7_1353800 & No model \\
\hline 3 & Q8IDG2 & 1RYP/D/R & $1 \mathrm{IRU} / \mathrm{D} / \mathrm{R}$ & PF3D7_1353900 & MAL13P1.270 185 \\
\hline 4 & Q8IJT1 & $1 R Y P / L / Z$ & $1 \mathrm{IRU} / \mathrm{L} / \mathrm{Z}$ & PF3D7_1011400 & PF10_0111 1187 \\
\hline 5 & Q7K6A9 & 1RYP/N/2 & $1 \mathrm{IRU} / \mathrm{N} / 2$ & PF3D7_0803800 & MAL8P1.142 660 \\
\hline 6 & C6KST3 & $1 \mathrm{RYP} / \mathrm{B} / \mathrm{P}$ & $1 \mathrm{IRU} / \mathrm{B} / \mathrm{P}$ & PF3D7_0608500 & TR Q7RK69 \\
\hline 7 & Q816T3 & 1RYP/I/W & $1 \mathrm{IRU} / \mathrm{I} / \mathrm{W}$ & PF3D7_1328100 & PF13_0156 2140 \\
\hline 8 & Q8IBI3 & 1RYP/E/S & $1 \mathrm{IRU} / \mathrm{E} / \mathrm{S}$ & PF3D7_0727400 & PF07_0112912 \\
\hline 9 & Q81K90 & 1RYP/F/T & $1 \mathrm{IRU} / \mathrm{F} / \mathrm{T}$ & PF3D7_1474800 & PF14_0716 3046 \\
\hline 10 & Q8IKC9 & $1 \mathrm{RYP} / \mathrm{K} Y$ & $1 \mathrm{IRU} / \mathrm{K} Y$ & PF3D7_1470900 & No_ID \\
\hline 11 & Q8IAR3 & 1RYP/A/O & 1 IRU /A/O & PF3D7_0807500 & No_ID \\
\hline 12 & $\mathrm{COH} 4 \mathrm{E} 8$ & 1RYP/M/1 & $1 \mathrm{IRU} / \mathrm{M} / 1$ & PF3D7_0518300 & No_ID \\
\hline 13 & Q810U7 & 1RYP/HN & $1 \mathrm{IRU} / \mathrm{HN}$ & PF3D7_0931800 & No model \\
\hline 14 & 077396 & 1RYP/G/U & $1 \mathrm{IRU} / \mathrm{G} / \mathrm{U}$ & PF3D7_0317000 & PFC0745c 3667 \\
\hline
\end{tabular}

PDB chains corresponding to homologs of yeast and bovine 20 S proteasome subunits and the ModBase IDs for individual Pf $20 \mathrm{~S}$ proteasomal subunit models. 
Table 2 Excluded regions in the Pf 205 model and their corresponding subunits

\begin{tabular}{llll}
\hline S. No. & $\begin{array}{l}\text { Pf 20S proteasome } \\
\text { subunit sequences } \\
\text { UniProt accession code }\end{array}$ & $\begin{array}{l}\text { Excluded regions } \\
\text { in the model } \\
\text { (location) }\end{array}$ & $\begin{array}{l}\text { Number of } \\
\text { amino acid } \\
\text { residues }\end{array}$ \\
\hline 1 & Q8IJT1 & MVIAS.....DFHKG (N-ter) & 60 \\
2 & Q7K6A9 & NSQKYD.....EYKEI (middle) & 35 \\
3 & Q816T3 & MKLEY.....FRKTG (N-ter) & 41 \\
4 & Q8IBI3 & MFSTRSEY (N-ter) & 8 \\
& & IDMTA (C-ter) & 5 \\
5 & Q8IAR3 & MVRPSQ (N-ter) & 6 \\
6 & COH4E8 & MDLIL.....GRGFK (N-ter) & 28 \\
7 & Q8I0U7 & MDWN....TPISD (N-ter) & 29 \\
& & KGRFH.....KFNDY (middle) & 53 \\
\hline
\end{tabular}

due to the lack of suitable templates for modeling. The 'large' insertions of fifty four and thirty five amino acid residues are associated with the subunits (UniProt codes: Q8I0U7 and Q7K6A9, respectively).

Three-dimensional model of the Pf $20 \mathrm{~S}$ proteasome and the Plasmodia-specific 'large' insert sequences in some of the beta subunits

The quality of the Pf $20 \mathrm{~S}$ proteasome model evaluated using the PROCHECK program for the individual subunits identified $>90 \%$ residues in the 'allowed' regions of the Ramachandran Map suggesting the models are of good quality. A cartoon representation of the Pf $20 \mathrm{~S}$ model compared with the crystal structure of the yeast $20 \mathrm{~S}$ proteasome is shown in Figure 1(A). The overall fold of the CP is similar to that of the yeast $20 \mathrm{~S}$ proteasome. The cavity on the side of the $\alpha$-ring where the substrate enters the catalytic site is shown in Figure 1(B).

The 'large' inserts are known to correspond to coding regions of low complexity (LCRs) which are a feature of many proteins in plasmodia. Although, the structure of these inserts are not known, its function has been suggested in the obstruction of immune-dominant epitopes and the presentation of 'non-sense' epitopes that lead to an inefficient antibody response (Mordmüller et al. 2006). Our model of the Pf $20 \mathrm{~S}$ proteasome suggests that these 'large' inserts are distant from the catalytic sites and are not likely to interfere with catalytic activity. Our observations are consistent with earlier predictions that suggest that the structural integrity and protease function seem not to be affected due to the 'large' inserts (Mordmüller et al. 2006). Experimental studies aimed at truncating the 'large' inserts and re-design of the $\beta 1$ and $\beta 7$ subunits of the Pf $20 \mathrm{~S}$ proteasome guided by the equivalent yeast $20 \mathrm{~S}$ proteasome subunits may provide clues to decipher their role in the Pf $20 \mathrm{~S}$ proteasome. Examination of the sequences corresponding to the $\beta 1$ subunit from other plasmodia species reveals that the 'large' insert is a feature common to all plasmodia species analyzed in this work. The alignment of the corresponding sequences is shown in Figure 2.

\section{Comparison of the catalytic residues, substrate binding} pockets and residues involved in maintaining stability of the conformation of Thr1 in yeast and Pf 20S proteasomes The crystal structure of yeast 20S proteasome (Groll et al. 1997) revealed that the amino acid residues; Thr1, Asp17 and Lys33 are important for catalytic activity, Ser129, Asp166, Ser169 are important for maintaining stability of the Thr1 conformation and amino acid residues at positions; $1,20,31,35,45,49$ and 53 comprise the substrate binding pockets for proteolytic cleavage in the $\beta 1, \beta 2$ and $\beta 5$ catalytic subunits. The alignment of the amino acid sequences corresponding to the equivalent $\beta 1, \beta 2$ and $\beta 5$ catalytic subunits in the Pf $20 \mathrm{~S}$ proteasome relative to yeast and bovine $20 \mathrm{~S}$ proteasomes are shown in Figures 3 $(\mathrm{A}-\mathrm{C})$ and labeled according to the numbering in the yeast 20S proteasome crystal structure (PDB code: 2F16).

The amino acid residues in the different catalytic subunits of the yeast $20 \mathrm{~S}$ proteasome and the equivalent residues (substitutions) in the Pf $20 \mathrm{~S}$ proteasome are listed in Table 3.

The amino acid residues important for the catalytic activity in yeast $20 \mathrm{~S}$ proteasome and associated with the $\beta 1$ (PDB code: 2F16_N), $\beta 2$ (2F16_H) and $\beta 5$ (2F16_K) subunits are also present in the equivalent Pf $20 \mathrm{~S}$ proteasome subunits, suggesting their highly conserved nature and that these equivalent subunits in the Pf $20 \mathrm{~S}$ proteasome would also be associated with catalytic activity. The catalytic subunits in yeast $20 \mathrm{~S}$ proteasome are associated with P1 cleavage sites of chromogenic reporter groups, peptidylglutamyl-peptide hydrolytic (PGPH) or post-acidic $(\beta 1)$, trypsin-like or post-basic $(\beta 2)$, chymotrypsin-like or post-hydrophobic $(\beta 5)$ activities (Arendt \& Hochstrasser 1997). The substitutions observed in the corresponding subunits of the Pf $20 \mathrm{~S}$ proteasome at positions; 22, 31 and 35 and certain additional substitutions in some of the subunits at positions; 20,21, 49, 53 are likely to contribute to the substrate specificity of the Pf $20 \mathrm{~S}$ proteasome relative to yeast $20 \mathrm{~S}$ proteasome. The Pf $20 \mathrm{~S}$ proteasome also contains the novel catalytic $\beta 7$ subunit identified in bovine $20 \mathrm{~S}$ proteasome (Unno et al. 2002) as it is characterized by the conserved N-terminal Gly-Thr1 residues observed in the other catalytic subunits.

\section{Comparative analysis of interactions of the bortezomib inhibitor in the three catalytic subunits of Pf $20 \mathrm{~S}$ proteasome model and the crystal structure of yeast $20 \mathrm{~S}$ proteasome}

The crystal structure complex of yeast $20 \mathrm{~S}$ proteasome with the known inhibitor - bortezomib (N-[(1R)-1(dihydroxyboryl)-3-methylbutyl]-N-(pyrazin-2-ylcarbonyl)- 


\section{(A)}

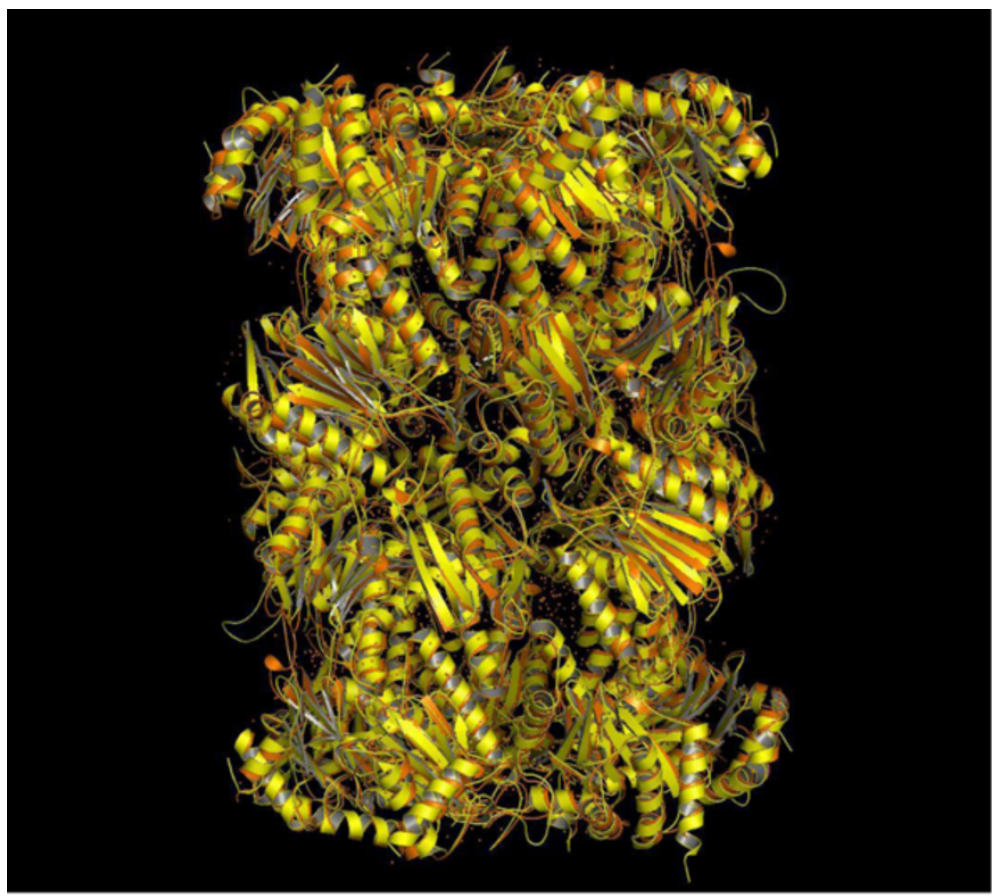

(B)

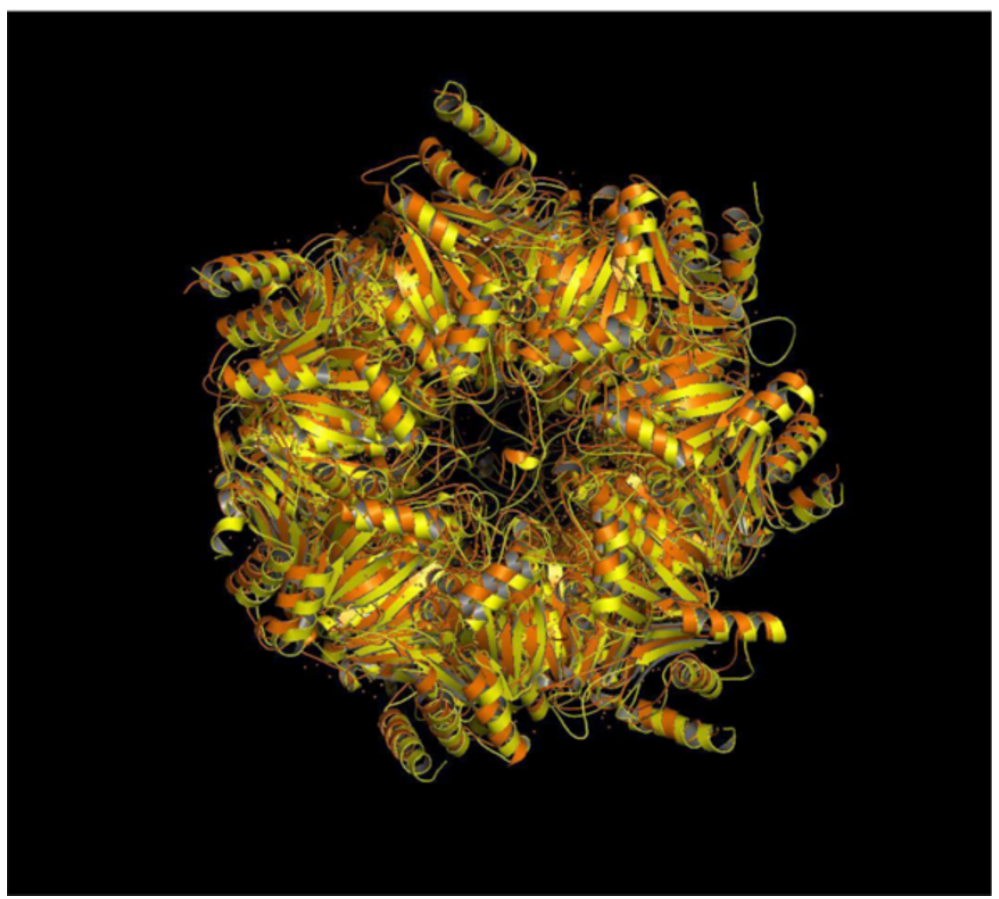

Figure 1 Schematic representation showing structural overlay of the crystal structure of yeast 20S proteasome [PDB code:1RYP] (orange) and the Pf $20 S$ proteasome model (yellow); (A) side-view and (B) top-view. 


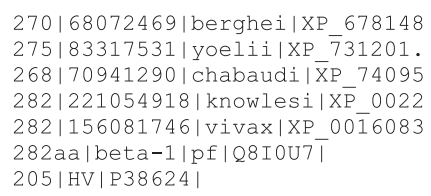

Figure 2 Multiple sequence alignment corresponding to the $\beta 1$ subunit sequences in Plasmodium falciparum and 5 other Plasmodium species and the yeast $20 \mathrm{~S}$ proteasome. The 'large' insert region is common to the $20 \mathrm{~S}$ proteasomes of the Plasmodium species analyzed. ${ }^{\prime *}$ ' indicates identical residues, ' $:$ ' indicates conservative substitutions, '.' indicates $>50 \%$ of residues are conserved in the alignment.
------MKIYNINQDS INNEYNIRTP ISDGTTI I GI IYEHGVMLACDTRT MEIEP-MKIYNINQDS INNEYNIRTPISDGTTI I GI I YEHGVMLACDTRT --MYKINQDS INNEYDIRTPISDGTTIIGIIYEHGVMLACDTRT MEVES-MKAELMGAPLREDPYDIKTPISDGTTIIGIIYEHGVMLACDTRT MOVER-MEADFMGAPLREDPYNIKTPISDGTTITGI TYEHGVMLACDTRT MDVVNESQIKCHEEKSWDDEYDIKTPISDGTTIIGIIYDNGVMLACDSRT --------MNGIQVDINRLKKGEVSLGTS IMAVTFKDGVILGADSRT

SSGTFVSNKCSRKINRINENIYVCRSGASAHSQKVIEVIKHYCASMKSEN SSGTFVSNKCSRKINRINENIYVCRSGASAHSQKVIEVIKHYCASMKSEN SSGTFVSNKCSRKINRINENIYVCRSGASAHSQKVIEVIKHYCASMKSEN SSGTLISNKCSRKINRINENIYACRSGASAHSQKVIELIKYFCLSMKCEN SSGTLVSNKCSRKINRINENIYACRSGASAHSOKVIELIKHFCLSMKCEN SSGTFISNKCSRKINRINENLYVCRSGASAHSQKI IEI IKHYCVSMKNEN TTGAYIANRVTDKLTRVHDKIWCCRSGSAADTQAIADIVQYHLELYTSQY

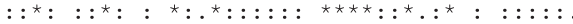

RKKGRFHENEVITDDINDEF-TDTDOTNN---INNN---NVTAKNKYYYN RKKGRFHENEVITDDINDEE-IDINQINN---INNN---NVIAKNKYYYD RKKGRFHEDEI I TDDINDEE-IDVNQINN---INNN---SVIAQNKYYYD RKKGRFHEDEVITDDLANEEDIDINAINNPFGLAQNGDPNYVTKHKYFYE RKKGRFHEDEVITDDLANEEDIDLSAINNPFGLAQNMDPNYVTKHKYFYE RKKGRFHEGETIYDETTYDEE IDIDS INY-LDYNNNNDNNLVTKNKYFYE

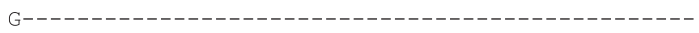

DKFMDYNPLVENVAYITKKLIYANNNFLSCGLIFGGYDKIKKQQLYSVNL DKFMDYNPLVENVAYITKKLVYANNNFLSCGLIFGGYDKIKKQQLYSVNL DKFMDYNPLVENVAYITKKLIYANNNFLSCGLIFGGYDKVKKOOLYSVNL DKFMDFNPPVENVAHMTKKLLYANNNFLSCGLILGGYDKDKKQQLYSINL DKFMDFNPLVENVAHMTKKLLYANNHFLSCGLILGGYDKEKKQQLYSVNL DKFNDYNPLVENVAH ITKK I I YTNNNFLSCALIFGGYDKIKKQQLYAVNL --- - TPSTETAASVFKELCYENKDNLTAGI IVAGYDDKNKGEVYTIPI

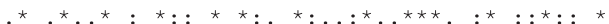
NGSIIQKYDYAVSGSGSIYIQSYLQDKYKKNMTKKECFDLILNCVKYAIY NGSI IOKHDYAVSGSGSIYIQSYLQDKYKQNMTKKECFDLILNCVKYAIY NGSIVQRFDYAVSGSGSVYIQSYLQDKYKKNMSKKECFELILGCVKYAMY NGSIVQRFDYAVSGSGSVYIQSYLQDKYKKNMSKKECEELILGCVKYAMY NGS I IEKHDFAVSGSGS IYIQSYLQDKYKKFMTKKECFNL I LNCVKYAMH GG-SVHKLPYAIAGSGSTFIYGYCDKNFRENMSKEETVDFIKHSLSQAIK

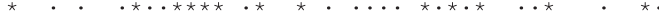

NDNSSGGIVRILNITKNFVEEYTITNTQIHFDY NDNSSGGIVRILNITKNYVEEYTVTNTQIHFDY NDNSSGGIIRILNITKLFVEEYTVTNTQIHFDY NDNSSGGIVRIVNITKLFVEEFTVTNTOLHFDY NDNSSGGIVRIVNMTKLFVEEFTVTNTOLHFDY NDNSSGGLIRIVNITKSFVEEFTVVNTQMNFQY WDGSSGGVIRMVVLTAAGVERLIFYPDEYEQL$: \quad:^{\star}{ }^{\star *}:{ }^{\star}: .: \quad:{ }^{* *}:{ }^{*} .{ }^{*}:{ }^{*}$

NGS I IQKYDYAVSGSGSIYIQSYLQDKYKKNMTKKECFDLILNCVKYAIY
L-phenylalaninamide) (PDB code:2F16) in the three catalytic sites; $\beta 1, \beta 2$ and $\beta 5$ provided the structural basis at atomic resolution for the different in vivo binding affinities of bortezomib for the individual subunits that are roughly attributed to the interactions of the leucine, pyrazine and boronate moieties (Groll et al. 2006). Our docking results were able to successfully reproduce the binding mode of bortezomib as observed in the crystal structure of the yeast $20 \mathrm{~S}$ proteasome-bortezomib complex (PDB code: 2F16). The structural overlay showing the cartoon representation of the crystal structure of yeast $20 \mathrm{~S}$ proteasome with bortezomib inhibitor (orange) (PDB code: 2F16) and bortezomib docked in the three-dimensional model of the Pf $20 \mathrm{~S}$ proteasome (yellow) corresponding to the $\beta 1, \beta 2$ and $\beta 5$ subunits are shown in Figures $4[\mathrm{~A}, \mathrm{~B}, \mathrm{C}]$, respectively. These figures demonstrate the overall structural similarity of the catalytic subunits in yeast and Pf $20 \mathrm{~S}$ proteasomes and the similar binding modes of bortezomib in the equivalent subunits. The magnified images of the docked bortezomib inhibitor (Figures 4D, E and F) shows its binding mode in the $\beta 1, \beta 2$ and $\beta 5$ subunits, respectively. The $\beta 2$ subunit of the Pf $20 \mathrm{~S}$ proteasome is associated with a relative displacement of the pyrazine moiety of bortezomib (Figure 4E) compared to that in yeast $20 \mathrm{~S}$ proteasome.

The intermolecular interaction energies obtained from AutoDock for binding of bortezomib within the equivalent catalytic subunits of yeast and Pf $20 \mathrm{~S}$ proteasomes are shown in Table 4.

Despite the observed substitutions in the equivalent catalytic subunits of the Pf $20 \mathrm{~S}$ proteasome relative to yeast $20 \mathrm{~S}$ proteasome, most hydrogen bond interactions between bortezomib and yeast $20 \mathrm{~S}$ proteasome are also present in the models of the Pf $20 \mathrm{~S}$ proteasomebortezomib complex as shown in Figures 5(A-C). 


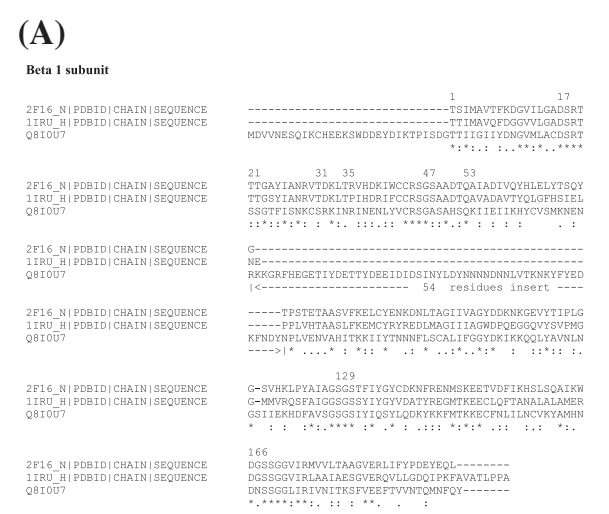

(C)

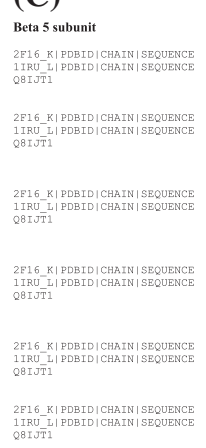

Figure 3 Multiple sequence alignment corresponding to (A) $\beta 1$, (B) $\beta 2$ and (C) $\beta 5$ subunit sequences of the yeast $20 \mathrm{~S}$ proteasome [PDB code:2F16], bovine 20S proteasome [PDB code:1IRU] and Pf 20S proteasome [UniProt codes]. Residue labeling is according to PDB code:2F16.

In the $\beta 1$ subunit of the yeast $20 \mathrm{~S}$ proteasome (PDB code:2F16, N-chain), the bortezomib inhibitor (BO2 1404) makes hydrogen bond interactions with residues in the binding pockets involving the main-chain atoms of Thr21, Gly47, Ala49 and side-chain atom of Thr22 and both main-chain and side-chain atoms of Thr1 (Groll et al. 2006). By comparison, all the above interactions are also observed in the corresponding $\beta 1$ subunit of the Pf $20 \mathrm{~S}$ proteasome (Figure 5A). The equivalent hydrogen-bond interactions with bortezomib at positions 21 and 22 are also conserved despite the substitutions; Thr21-Ser, Thr22-Ser, as serine only lacks the side-chain $\mathrm{C}$-gamma atom compared with threonine. The Ala49-Ser mutation contributes an extra hydrogen-bond interaction via the side-chain OG atom of serine in the Pf $20 S$ proteasome $\beta 1$ subunit relative to yeast $20 \mathrm{~S}$ proteasome favoring better binding interactions to bortezomib.

In the $\beta 2$ subunit of the yeast $20 \mathrm{~S}$ proteasome (PDB code:2F16, H-chain), bortezomib (BO2 1400) makes hydrogen bond interactions with residues in the binding site pockets involving the main-chain atoms of Thr21, Gly47, Ala49 and side-chain atom of Ser20 and both the main-chain and side-chain atoms of Thr1 (Groll et al. 2006). All these interactions are also observed in the
(B)
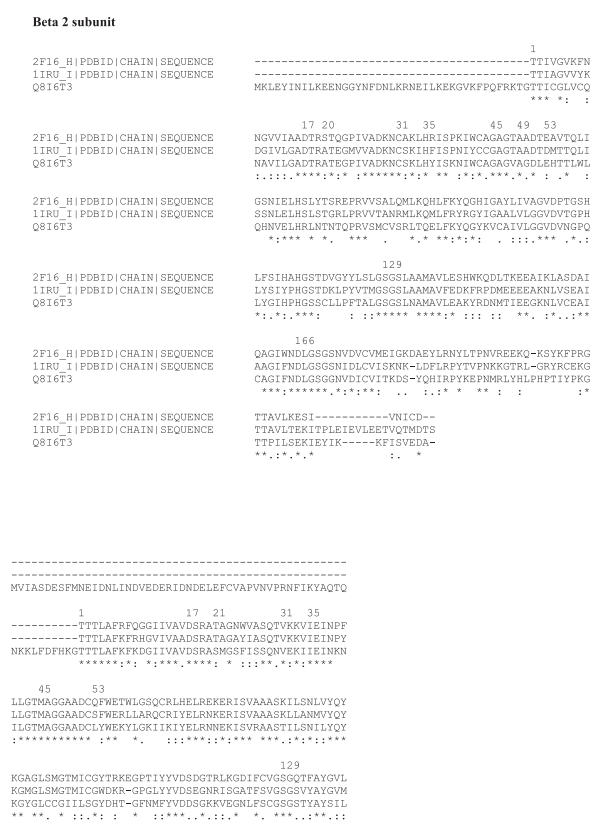

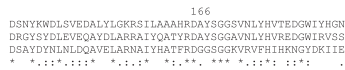

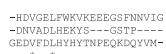

corresponding $\beta 2$ subunit of the Pf $20 \mathrm{~S}$ proteasome except the side-chain hydrogen-bond interaction with bortezomib due to the Ser20-Ala substitution (Figure 5B). Further, the side-chain hydrogen bond interactions made by Thr22 in the $\beta 1$ subunit of yeast $20 \mathrm{~S}$ proteasome is not observed at the equivalent position in the $\beta 2$ subunit of both yeast and Pf $20 \mathrm{~S}$ proteasomes due to substitutions by Gln22 and Glu22, respectively. For these reasons, the pyrazine moiety of bortezomib is not likely to make any interaction with protein residues in the $\beta 2$ subunits of both yeast and Pf $20 \mathrm{~S}$ proteasomes. Further, the Ser20Ala substitution may contribute to the relative displacement (weaker binding) of bortezomib in the $\beta 2$ subunit of Pf $20 \mathrm{~S}$ proteasome compared to that in the yeast $20 \mathrm{~S}$ proteasome (see Figures $4 \mathrm{E}$ and $5 \mathrm{E}$ ). The phenylalanine ring is 'flipped' relative to the other two catalytic subunits and it has been suggested that the P2 site of bortezomib possibly contributes to overall pharmacodynamic properties, but not kinetics of inhibition (Groll et al. 2006). In case of the $\beta 2$ subunit of Pf $20 \mathrm{~S}$ proteasome too, the phenylalanine moiety is exposed to the surface and is 'flipped' relative to its conformation in the $\beta 1$ and $\beta 5$ catalytic subunits as observed in the $\beta 2$ subunit of the yeast $20 \mathrm{~S}$ proteasome. The binding affinity of bortezomib in the $\beta 2$ subunit of Pf $20 \mathrm{~S}$ 
Table 3 Amino acid residues in $\beta 1, \beta 2, \beta 5$ catalytic subunits in yeast $20 \mathrm{~S}$ proteasome (PDB code: 2F16:N,H,K-chains, respectively) and equivalent residues (substitutions) in Pf 205 proteasome associated with the catalytic sites, substrate binding pockets, maintenance of stability of Thr1 and interactions with the bortezomib inhibitor

\begin{tabular}{cccc}
\hline Residue Number & \multicolumn{3}{c}{ Catalytic subunits } \\
\cline { 2 - 4 } & $\boldsymbol{\beta} \mathbf{1}$ & $\boldsymbol{\beta 2}$ & $\boldsymbol{\beta} 5$ \\
\hline 1 & $\mathrm{~T}$ & $\mathrm{~T}$ & $\mathrm{~T}$ \\
17 & $\mathrm{D}$ & $\mathrm{D}$ & $\mathrm{D}$ \\
20 & $\mathrm{~T}$ & $\mathrm{~S}(\mathrm{~A})$ & $\mathrm{A}$ \\
21 & $\mathrm{~T}(\mathrm{~S})$ & $\mathrm{T}$ & $\mathrm{T}(\mathrm{S})$ \\
22 & $\mathrm{~T}(\mathrm{~S})$ & $\mathrm{Q}(\mathrm{E})$ & $\mathrm{A}(\mathrm{M})$ \\
31 & $\mathrm{~T}(\mathrm{~S})$ & $\mathrm{C}$ & $\mathrm{V}$ \\
33 & $\mathrm{~K}$ & $\mathrm{~K}$ & $\mathrm{~K}$ \\
35 & $\mathrm{~T}(\mathrm{~N})$ & $\mathrm{H}$ & $\mathrm{I}$ \\
45 & $\mathrm{R}$ & $\mathrm{G}$ & $\mathrm{M}$ \\
47 & $\mathrm{G}$ & $\mathrm{G}$ & $\mathrm{G}$ \\
49 & $\mathrm{~A}(\mathrm{~S})$ & $\mathrm{A}$ & $\mathrm{A}$ \\
53 & $\mathrm{Q}$ & $\mathrm{E}$ & $\mathrm{Q}(\mathrm{L})$ \\
129 & $\mathrm{~S}$ & $\mathrm{~S}$ & $\mathrm{~S}$ \\
166 & $\mathrm{D}$ & $\mathrm{D}$ & $\mathrm{D}$ \\
169 & $\mathrm{~S}$ & $\mathrm{~S}$ & $\mathrm{~S}$ \\
\hline
\end{tabular}

proteasome may therefore be lower compared to its binding in the $\beta 2$ subunit of the yeast $20 \mathrm{~S}$ proteasome as reflected in the relatively higher intermolecular energies for bortezomib binding to the $\beta 2$ subunit of Pf $20 \mathrm{~S}$ proteasome shown in Table 4. Moreover, it is also known that bortezomib has least preference for the $\beta 2$ subunit in the yeast $20 \mathrm{~S}$ proteasome (Berkers et al. 2005). The Glu22 in $\beta 2$ subunit of the Pf $20 \mathrm{~S}$ proteasome has two oxygen atoms (OE1, OE2) in its side-chain when compared with Gln22 in yeast $20 \mathrm{~S}$ proteasome that may be exploited in designing suitable bortezomib analogs that make favourable interaction with the inhibitor in the $\beta 2$ subunit of Pf $20 \mathrm{~S}$ proteasome.

Finally, in the $\beta 5$ subunit of the yeast $20 \mathrm{~S}$ proteasome (PDB code:2F16, K-chain), bortezomib (BO2 1402) makes hydrogen bond interactions with residues in the binding pockets involving the main-chain Thr21, Gly47, Ala49 and main-chain and side-chain of Thr1 (Groll et al. 2006). These interactions are also observed in the corresponding $\beta 5$ subunit of the Pf $20 \mathrm{~S}$ proteasome (Figure $5 \mathrm{C}$ ). The Thr21-Ser substitution in the $\beta 5$ subunit of the Pf $20 \mathrm{~S}$ proteasome does not affect the hydrogen-bond interactions with bortezomib. All other residues comprising the inhibitor binding pocket remaining the same, the substitutions; Ala22-Met, Gln53-Leu in the $\beta 5$ subunit of the Pf
$20 \mathrm{~S}$ proteasome may affect the relative chymotryptic-like activity compared with the yeast $20 \mathrm{~S}$ proteasome.

The preference for the affinity of bortezomib to the $\beta 5$ subunit relative to the other two catalytic subunits in yeast $20 \mathrm{~S}$ proteasome, i.e., $\beta 5>\beta 1>>\beta 2$ (Berkers et al. $2005)$ is reflected in the low intermolecular interaction energy for the $\beta 5$ subunit $(-6.84 \mathrm{kcal} / \mathrm{mol})$ as shown in Table 4. In Pf $20 \mathrm{~S}$ proteasome, however, bortezomib appears to have a preference for the $\beta 1$ subunit as inferred from the relative intermolecular interaction energies. The observed substitutions in the $\beta 1$ and $\beta 5$ subunits of the Pf $20 \mathrm{~S}$ proteasome compared to the yeast $20 \mathrm{~S}$ proteasome mentioned earlier may contribute to the relative preference for bortezomib inhibition. Accordingly, bortezomib inhibition may influence the caspase-like and chymotryptic-like activities in Pf $20 \mathrm{~S}$ proteasome compared to that in yeast $20 \mathrm{~S}$ proteasome. The binding affinity of bortezomib to the $\beta 2$ subunit of the Pf $20 \mathrm{~S}$ proteasome is least as inferred from the relative high intermolecular interaction energy value $(-1.54 \mathrm{kcal} / \mathrm{mol})$ possibly due to the loss of side-chain hydrogen-bond interactions in the $\beta 2$ subunit of the Pf $20 S$ proteasome due to Ser20Ala substitution.

In an earlier comprehensive study on the proteasome inhibitors against Plasmodium falciparum laboratory strains, bortezomib inhibitory activity was observed to be low (Kreidenweiss et al. 2008) in contrast to multiple myeloma treatment (Rajkumar et al. 2005). Our analysis is in agreement with the above experimental observations. Bortezomib is capable of binding to the equivalent catalytic subunits of the Pf $20 \mathrm{~S}$ proteasome although relatively less efficiently as reflected in the relatively higher intermolecular energy values for the Pf $20 \mathrm{~S}$ proteasome shown in Table 4. The lower efficiency of bortezomib binding in the catalytic subunits of Pf $20 \mathrm{~S}$ proteasome relative to yeast $20 S$ proteasome may be due to the observed substitutions within the bortezomib binding pockets. Also, the substitutions described for the Pf $20 \mathrm{~S}$ proteasome contribute to the different charge patterns and overall architecture (see Figures 5D, E and F) as observed in the yeast $20 \mathrm{~S}$ proteasome (Groll et al. 2006).

The binding mode of bortezomib inhibitor is similar to that observed in the catalytic subunits of the yeast $20 \mathrm{~S}$ proteasome, except in the $\beta 2$ subunit of the Pf $20 \mathrm{~S}$ proteasome where there is a relative displacement due to the observed substitution. Therefore, the substitutions identified in the equivalent catalytic subunits of the Pf $20 \mathrm{~S}$ proteasome compared to the yeast $20 \mathrm{~S}$ proteasome may only affect the relative caspase-like, tryptic-like and chymotryptic-like activities although bortezomib binding may not be largely affected. The phenylalanine moiety of bortezomib is exposed and does not make interactions with the protein subunits also in the Pf $20 \mathrm{~S}$ proteasome as is observed in the yeast $20 \mathrm{~S}$ proteasome. Our models 

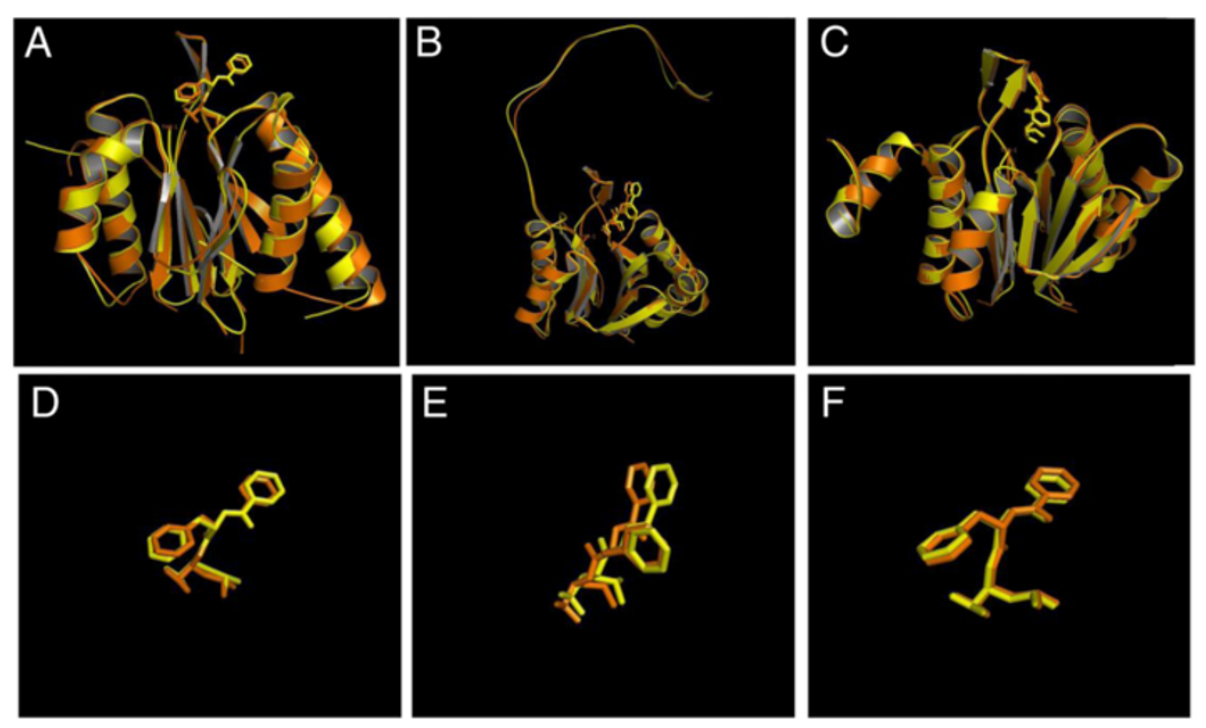

Figure 4 Schematic representations of the structural overlay corresponding to the crystal structure of the yeast $20 \mathrm{~S}$ proteasome bortezomib inhibitor complex [PDB code:2F16] (orange) and the model of the Pf $20 \mathrm{~S}$ proteasome with docked bortezomib inhibitor (yellow) in the catalytic sites of (A) $\beta 1,(B) \beta 2$ and (C) $\beta 5$ subunits. Magnified images of the bortezomib inhibitors (in stick representation) are shown for the above subunits in (D), (E) and (F), respectively.

of the Pf $20 \mathrm{~S}$ proteasome with bortezomib provide the structural basis for rational design of Pf $20 \mathrm{~S}$ proteasome specific inhibitors.

We suggest other possible strategies for Pf $20 \mathrm{~S}$ proteasome inhibition, such as, to design suitable compounds that block interactions at the interface of $\alpha / \beta, \alpha / \alpha$ or $\beta / \beta$ subunits, as it is understood that the $\alpha$ and $\beta$ subunits are formed first with subsequent formation of the seven membered ring (Wolf \& Hilt 2004). Further, the formation of the active $20 \mathrm{~S}$ proteasome is preceded by the cleavage of its pro-sequence. Therefore, the structure of the inactive catalytic subunit with the pro-sequence bound may provide clues to designing suitable inhibitors. As high resolution structural data for the regulatory subunits become available, it would provide further opportunities for the design of compounds that inhibit substrate

Table 4 Intermolecular interaction energies of Bortezomib (Velcade ${ }^{\circledR}$ ) inhibitor in the catalytic subunits of the crystal structure of yeast $20 \mathrm{~S}$ proteasome and in the equivalent subunits of the Pf 205 proteasome model

\begin{tabular}{cc}
\hline Catalytic subunits & Intermolecular Energy (kcal/mol) \\
\hline 2F16_Beta1 & -6.45 \\
2F16_Beta2 & -6.60 \\
2F16_Beta5 & -6.84 \\
Pf_Beta1 & -5.84 \\
Pf_Beta2 & -1.54 \\
Pf_Beta5 & -4.29 \\
\hline
\end{tabular}

recognition or molecular events that guide the entry of the substrate towards the catalytic core. The availability of a number of other proteasome inhibitors (Kreidenweiss et al. 2008; Buac et al. 2013) provides an opportunity to carry out docking studies with these compounds in the three-dimensional models of the Pf $20 \mathrm{~S}$ proteasome that are relevant for malaria therapeutics.

Finally, another observation that we have made, although not related to the Pf $20 \mathrm{~S}$ proteasome catalytic sites is the comparison of sequences of the $20 \mathrm{~S}$ proteasomes of bovine, yeast and Pf with regard to the Nuclear Localization Signal (NLS). The bovine 20S proteasome contains a sequence motif [X-X-K-K(R)-X-K (R)] associated with the $\alpha 1-\alpha 4$ subunits needed for its import into nucleus by the importin- $\alpha$ receptor (Unno et al. 2002). This sequence motif is not present in the equivalent $\alpha$ subunits of the Pf and yeast $20 \mathrm{~S}$ proteasomes as shown in Table 5.

\section{Conclusions}

The three-dimensional model of the Pf $20 \mathrm{~S}$ proteasome complexed with the bortezomib inhibitor supports previous experimental studies that demonstrate bortezomib inhibition of the Pf $20 \mathrm{~S}$ proteasome and further elucidates its binding mode within the catalytic subunits. The affinity for bortezomib binding to the Pf laboratory strains is known to be low in contrast to binding eukaryotic $20 \mathrm{~S}$ proteasome as evinced from multiple myeloma treatment and the relative intermolecular interaction energies 

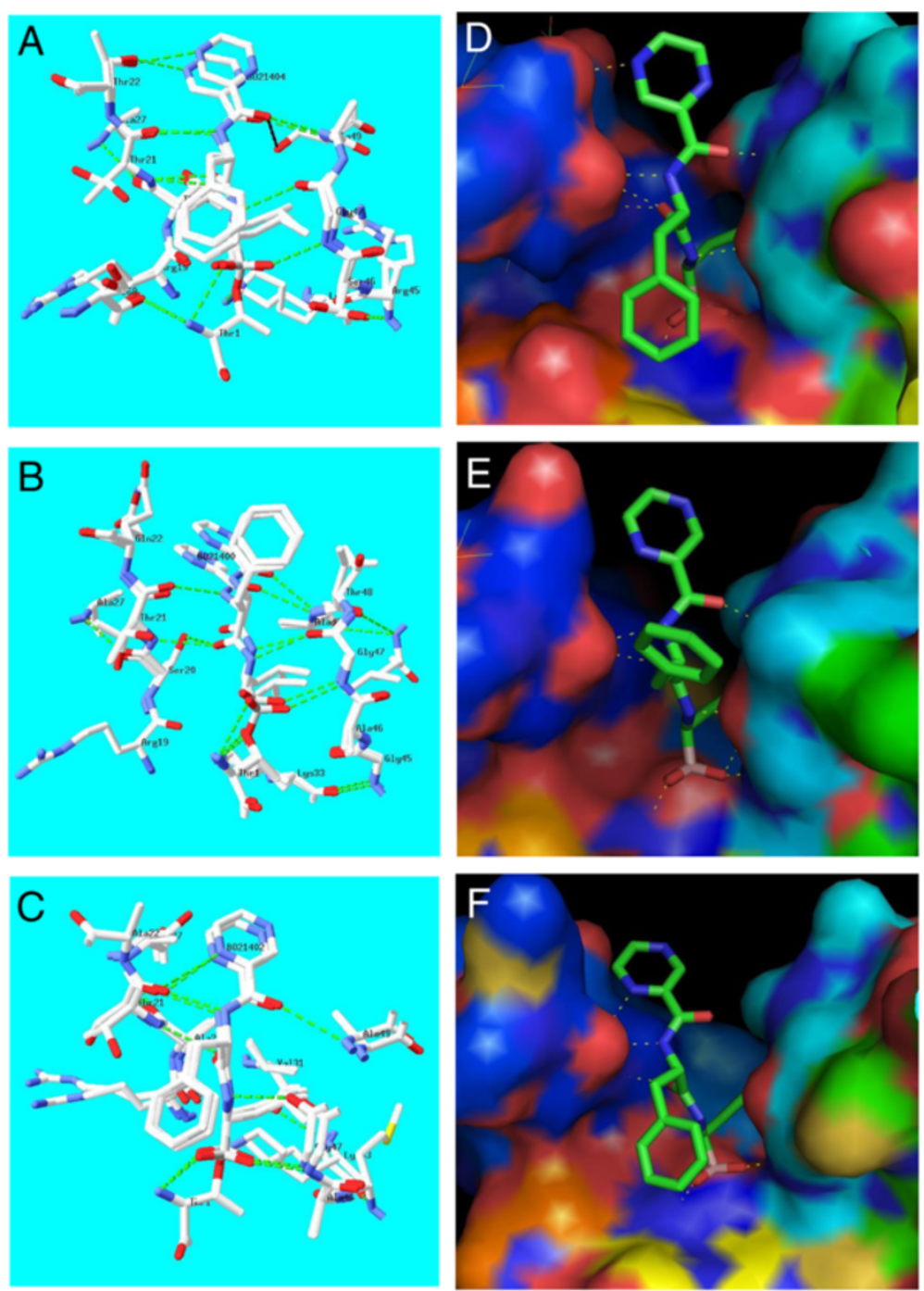

Figure 5 Structural superposition of the yeast 20S proteasome - bortezomib inhibitor crystal structure complex [PDB code:2F16] and Pf $20 \mathrm{~S}$ proteasome - bortezomib model showing inter-molecular hydrogen bond interactions and residues close to the inhibitor defined by a $4.0 \AA$ A cut-off value in (A) $\beta 1,(B) \beta 2$ and (C) $\beta 5$ subunits. The electrostatic charge surface (red;electronegative, blue;electropositive) for the Pf $20 \mathrm{~S}$ proteasome model with bound bortezomib for the above subunits are shown in figures (D), (E) and (F), respectively.

obtained from our docking studies is consistent with the above results. Further, our docking analysis suggests a relative preference for bortezomib binding to the $\beta 1$ subunit in the Pf $20 \mathrm{~S}$ proteasome. The amino acid residue substitutions identified within the catalytic subunits

Table 5 Nuclear localization signal [X-X-K-K(R)-X-K(R)] in bovine $20 S$ proteasome and equivalent amino acid sequence in $\mathrm{Pf}$ and yeast $20 \mathrm{~S}$ proteasomes

\begin{tabular}{llll}
\hline Alpha subunits & Bovine & Pf & Yeast \\
\hline 1 & LEKKVK $(179-184)$ & LERLLE & LENHFK \\
2 & TEKKQK(47-52) & TEKKSP & TEKKSS \\
3 & REKKEK(249-254) & ---- & EEADED \\
4 & EKKKQK(240-245) & NEQNE- & QEQDKK \\
\hline
\end{tabular}

are useful candidates for evaluating the structureactivity relationship of the Pf $20 \mathrm{~S}$ proteasome. Our models provide the structural basis for rational design of Pf $20 \mathrm{~S}$ proteasome-specific catalytic site inhibitory compounds among other strategies that exploit structural information for the purpose of drug design.

\section{Competing interests}

The authors declare that they have no competing interests.

\section{Authors' contributions}

SS and GB carried out modeling and docking studies, KG designed the studies and drafted the manuscript. All authors read and approved the final manuscript.

\section{Acknowledgements}

The authors acknowledge the support of CSIR and DBT, Government of India. 
Received: 17 September 2013 Accepted: 11 October 2013

Published: 26 October 2013

\section{References}

The PyMOL Molecular Graphics System, Version 1.5.0.4. LLC, Schrödinger

Adams J, Behnke M, Chen S, Cruickshank AA, Dick LR, Grenier L, Klunder JM, Ma YT, Plamondon L, Stein RL (1998) Potent and selective inhibitors of the proteasome: dipeptidyl boronic acids. Bioorg Med Chem Lett 8:333-338

Altschul SF, Madden TL, Schäffer AA, Zhang J, Zhang Z, Miller W, Lipman DJ (1997) Gapped BLAST and PSI-BLAST: a new generation of protein database search programs. Nucleic Acids Res 25:3389-3402

Arendt CS, Hochstrasser M (1997) Identification of the yeast 20 S proteasome catalytic centers and subunit interactions required for active-site formation. Proc Natl Acad Sci U S A 94:7156-7161

Aurrecoechea C, Brestelli J, Brunk BP, Dommer J, Fischer S, Gajria B, Gao X, Gingle A Grant G, Harb OS, Heiges M, Innamorato F, lodice J, Kissinger JC, Kraemer E, Li W, Miller JA, Nayak V, Pennington C, Pinney DF, Roos DS, Ross C, Stoeckert CJ Jr, Treatman C, Wang H (2009) PlasmoDB: a functional genomic database for malarial parasites. Nucleic Acids Res 37:D539-D543

Berkers CR, Verdoes M, Lichtman E, Fiebiger E, Kessler BM, Anderson KC, Ploegh HL, Ovaa H, Galardy PJ (2005) Activity probe for in vivo profiling of the specificity of proteasome inhibitor bortezomib. Nat Methods 2:357-362

Bochtler M, Ditzel L, Groll H, Hartmann C, Huber R (1999) The proteasome. Annu Rev Biophys Biomol Struct 28:295-317

Buac D, Shen M, Schmitt S, Kona FR, Deshmukh R, Zhang Z, Neslund-Dudas C, Mitra B, Dou QP (2013) From bortezomib to other inhibitors of the proteasome and beyond. Curr Pharm Des 19:1-14

Coux O, Tanaka K, Goldberg AL (1996) Structure and functions of the 205 and 265 proteasomes. Annu Rev Biochem 65:801-847

Dahlmann B (2007) Role of proteasome in disease. BMC Biochem 8:1-12

DeMartino GN, Slaughter CA (1999) The proteasome, a novel protease regulated by multiple mechanisms. J Biol Chem 274:22123-22126

Eswar N, Eramian D, Webb B, Shen MY, Sali A (2008) Protein structure modeling with MODELLER. Methods Mol Biol 426:145-159

Förster F, Lasker K, Nickell S, Sali A, Baumeister W (2010) Toward an integrated structural model of the $26 \mathrm{~S}$ proteasome. Molecular and Cellular Proteomics 9:1666-1677

Groll M, Huber R (2004) Inhibitors of the eukaryotic 20S proteasome core particle: a structural approach. Biochim Biophys Acta 1695:33-44

Groll M, Ditzel L, Löwe J, Stock D, Bochtier M, Bartunik HD, Huber R (1997) Structure of $20 S$ proteasome from yeast at $2.4 \AA$ resolution. Nature 386:463-471

Groll M, Berkers CR, Ploegh HL, Ovaa H (2006) Crystal structure of the boronic acid-based proteasome inhibitor bortezomib in complex with the yeast 205 proteasome. Structure 14:451-456

Guex N, Peitsch MC (1997) SWISS-MODEL and the swiss-PdbViewer: an environment for comparative protein modeling. Electrophoresis $18: 2714-2723$

Heinemeyer W, Fischer M, Krimmer T, Stachon U, Wolf DH (1997) The Active Sites of the eukaryotic $20 \mathrm{~S}$ proteasome and their involvement in subunit precursor processing. J Biol Chem 272:25200-25209

Hershko A, Ciechanover A (1998) The ubiquitin system. Annu Rev Biochem 67:425-479

Jung T, Grune T (2012) Structure of the proteasome. Prog Mol Biol Transl Sci 109:1-39

Kisselev AF, Goldberg AL (2001) Proteasome inhibitors: from research tools to drug candidates. Chem Biol 8:739-758

Kreidenweiss A, Kremsner PG, Mordmüller B (2008) Comprehensive study of proteasome inhibitors against Plasmodium falciparum laboratory strains and field isolates from Gabon. Malar J 7:187-194

Lander GC, Estrin E, Matyskiela ME, Bashore C, Nogales E, Martin A (2012) Complete subunit architecture of the proteasome regulatory particle. Nature 482:186-191

Lasker K, Förster F, Bohn S, Walzthoeni T, Villa E, Unverdorben P, Beck F, Aebersold R, Sali A, Baumeister W (2012) Molecular architecture of the 265 proteasome holocomplex determined by an integrated approach. Proc Natl Acad Sci U S A 109:1380-1397

Laswoski RA, MacArthur MW, Moss DS, Thornton JM (1993) PROCHECK - a program to check the stereochemical quality of protein structures. J Appl Crystallogr 26:283-291
Ludwig H, Khayat D, Giaccone G, Facon T (2005) Proteasome inhibition and its clinical prospects in the treatment of hematologic and solid malignancies. Cancer 104:1794-1807

Marques AJ, Palanimurugan R, Matias AC, Ramos PC, Dohmen RJ (2009) Catalytic mechanism and assembly of the proteasome. Chem Rev 109:1509-1536

Mordmüller B, Fendel R, Kreidenweiss A, Gille C, Hurwitz R, Metzger WG, Kun JF, Lamkemeyer T, Nordheim A, Kremsner PG (2006) Plasmodia express two threonine-peptidase complexes during asexual development. Mol Biochem Parasitol 148:79-85

Morris GM, Huey R, Lindstrom W, Sanner MF, Belew RK, Goodsell DS, Olson AJ (2009) Autodock4 and AutoDockTools4: automated docking with selective receptor flexibility. J Comput Chem 16:2785-2791

Myung J, Kim KB, Crews CM (2001) The ubiquitin-proteasome pathway and proteasome inhibitors. Med Res Rev 21:245-273

Nickell S, Beck F, Scheres SHW, Korinek A, Förster F, Lasker K, Mihalache O, Sun N, Nagy I, Sali A, Plitzko JM, Carazo JM, Mann M, Baumeister W (2009) Insights into the molecular architecture of the 265 proteasome. Proc Natl Acad Sci U S A 106:11943-11947

Pickart CM (2001) Mechanisms underlying ubiquitination. Annu Rev Biochem 70:503-533

Pieper U, Webb BM, Barkan DT, Schneidman-Duhovny D, Schlessinger A, Braberg H, Yang Z, Meng EC, Pettersen EF, Huang CC, Datta RS, Sampathkumar P, Madhusudhan MS, Sjolander K, Ferrin TE, Burley SK, Sali A (2011) MODBASE, a database of annotated comparative protein structure models and associated resources. Nucleic Acids Res 39:465-474

Rajkumar SV, Richardson PG, Hideshima T, Anderson KC (2005) Proteasome inhibition as a novel therapeutic target in human cancer. J Clin Oncol 23:630-639

Richardson PG, Sonneveld P, Schuster MW, Irwin D, Stadtmauer EA, Facon T, Harousseau JL, Ben-Yehuda D, Lonial S, Goldschmidt H, Reece D, San-Miguel JF, Bladé J, Boccadoro M, Cavenagh J, Dalton WS, Boral AL, Esseltine DL, Porter JB, Schenkein D, Anderson KC (2005) Bortezomib or high-dose dexamethasone for relapsed multiple myeloma. N Engl J Med 352:2487-2498

Rose PW, Bi C, Bluhm WF, Christie CH, Dimitropoulos D, Dutta S, Green RK, Goodsell DS, Prlic A, Quesada M, Quinn GB, Ramos AG, Westbrook JD, Young J, Zardecki C, Berman HM, Bourne PE (2013) The RCSB Protein Data Bank: new resources for research and education. Nucleic Acids Res 41:D475-D482

Saeki Y, Tanaka K (2012) Assembly and function of the proteasome. Methods Mol Biol 832:315-337

Sali A, Blundell TL (1993) Comparative protein modeling by satisfaction of spatial restraints. J Mol Biol 234:779-815

Teicher BA, Ara G, Herbst R, Palombella VJ, Adams J (1999) The proteasome inhibitor PS-341 in cancer therapy. Clin Cancer Res 5:2638-2645

The UniProt Consortium (2010) The Universal Protein Resource (UniProt) in 2010. Nucleic Acids Res 38:D142-D148

Thompson JD, Higgins DG, Gibson TJ (1994) CLUSTAL W: improving the sensitivity of progressive multiple sequence alignment through sequence weighting, position-specific gap penalties and weight matrix choice. Nucleic Acids Res 22:4673-4680

Unno M, Mizushima T, Morimoto Y, Tomisugi Y, Tsukihara T (2002) The structure of the Mammalian $20 S$ Proteasome at $2.75 \AA$ A resolution. Structure 10:608-618

Voges D, Zwickl P, Baumeister W (1999) The 265 proteasome, a molecular machine designed for controlled proteolysis. Annu Rev Biochem 68:1015-1068

Wallace AC, Laskowski RA, Thornton JM (1995) LIGPLOT: a program to generate schematic diagrams of protein-ligand interactions. Protein Eng 8:127-134

Wolf DH, Hilt W (2004) The proteasome: a proteolytic nanomachine of cell regulation and waste disposal. Biochim Biophys Acta 1695:19-31

doi:10.1186/2193-1801-2-566

Cite this article as: Sridhar et al:: Analysis of bortezomib inhibitor docked within the catalytic subunits of the Plasmodium falciparum 205 proteasome. SpringerPlus 2013 2:566. 